\title{
DOENCCA DE CHAGAS CONGÊNITA: AVALIAÇÃO IMUNOCITOQUÍMICA DO PARASITISMO EM TECIDOS DE FETO MACERADO
}

\section{Ana Maria A. Lana 1 Eliane Lages-Silva 2 e Alfredo J. A. Barbosa 1}

\begin{abstract}
$O$ método imunocitoquímico de peroxidase anti-peroxidase é aplicado, pela primeira vez, em tecidos de natimorto macerado de II-III graus para coloração especifica de amastigotas do Trypanosoma cruzi, em caso de doença de Chagas congênita. Os resultados mostram que o encontro de ninhos de amastigotas é muito facilitado pelo método, mesmo em tecidos autolisados, onde a morfologia dos parasitas geralmente se mostra muito alterada; o método é recomendável, também nestes casos, para a avaliação mais precisa da intensidade do parasitismo.
\end{abstract}

Palavras chaves: Peroxidade, anti-peroxidase. Doença de Chagas congênita. Maceração fetal. Trypanosoma cruzi.

A transmissão intra-uterina da doença de Chagas é demonstrada de modo definitivo, do ponto de vista histopatológico, pela presença do parasitismo nos tecidos fetais. Geralmente os órgãos mais atingidos são o coração, pele, pulmões, tubo digestivo, encéfalo, bexiga e o tecido muscular esquelético 13 . Entretanto, em número importante de casos, a transmissão congênita é observada em natimortos, muitas vezes macerados de II ou III graus 34 , quando a avaliação do parasitismo encontra-se prejudicada. Em consequêencia da autólise, as formas amastigotas apresentam-se morfologicamente alteradas, o cinetoplasto e o núcleo nem sempre mantêm-se conservados, impedindo ou dificultando o reconhecimento dos amastigotas em preparações histológicas convencionais, podendo inclusive ser confundidos com outros parasitas como o Toxoplasma gondi ${ }^{5}$.

Tendo em vista a utilização do método imunocitoquimico pela peroxidase anti-peroxidase (PAP) para a demonstração do $T$. cruzi em cortes histológicos de rotina ${ }^{2}$, resolveu-se aplicar o referido método em tecidos de feto macerado, com diagnóstico de doença de Chagas congênita. Deste modo, propõe-se avaliar a utilidade do método imunocitoquimico para odiagnóstico e quantificação do parasitismo neste tipo de material, na tentativa de se contornar as dificuldades acima descritas, quando se utilizam coloraçōes convencionais.

Trabalho realizado no Departamento de Anatomia Patológica e Medicina Legal (DAPML) da Faculdade de Medicina da UFMG com auxilio financeiro da FINEP e CNPq.

1. Faculdade de Medicina da Universidade Federal de Minas Gerais.

2. Centro de Pesquisas René Rachou - Fiocruz, Belo Horizonte, MG.

Endereço para correspondência: Dra. Ana Maria A. Lana, Departamento de Anatomia Patológica e Medicina Legal,

Faculdade de Medicina da UFMG, Av. Alfredo Balena 190 - 30000 Belo Horizonte, MG, Brasil.

Recebido para publicação em 2/7/1985.

\section{MATERIAL E MÉTODOS}

Os tecidos fetais foram obtidos de necrópsia de natimorto macerado de II para III grau, do sexo feminino, primeiro feto de parto gemelar, prematuro. A mãe apresentava-se assintomática, mas com sorologia positiva para doença de Chagas e eletrocardiograma demonstrando bloqueio de ramo direito. $\mathrm{O}$ segundo gêmeo nasceu vivo e o exame a fresco do sangue do cordão umbilical foi positivo para $T$. cruzi. $\mathrm{O}$ exame anátomo-patológico da placenta mostrou numerosos focos de inflamação e parasitismo acentuado. Fragmentos de órgãos fetais (Tabela 1) foram fixados em formol a $10 \%$, incluídos em parafina e corados rotineiramente pelo método da hematoxilina eosina (H.E.) e pelo método do PAP introduzido por Sternberger ${ }^{8}$ e utilizado por Barbosa ${ }^{2}$ para a demonstração de amastigotas do $T$. cruzi em cortes histológicos de rotina. Utilizou-se na técnica imunocitoquimica, anti-soro de coelho chagásico infectado com tripomastigotas cepa $\mathrm{CL}$, inóculo i.p. de $10^{7}$ tripomastigotas provenientes de camundongo irradiado. $\mathrm{O}$ anti-soro utilizado apresentava alta taxa de anticorpos liticos anti- $T$. cruzi como evidenciadas pela reação de lise mediada por complemento ${ }^{6} . \mathrm{O}$ anti-soro primário foi diluido em tampão fosfato salina (PBS), PH 7.2, na proporção 1:1000. Como anticorpo de ligação utilizou-se IgG de cabra anti-IgG de coelho (Miles-Yeda Ltd, Israel) diluido 1:80 em PBS com 0,1\% de albumina bovina. $\mathrm{Na}$ terceira camada, aplicou-se aos cortes o complexo peroxidase anti-peroxidase (coelho), diluído em PBS, i :200. O local da reação foi demonstrado utilizando-se como agente revelador 3,3 diamino-benzidina em solução de $30 \mathrm{mg} \%$ em PBS com $0,03 \%$ de peróxido de hidrogênio. Em seguida, os cortes foram contracorados com hematoxilina e montados entre lâmina e laminula como de rotina. Como controles positivos utilizaram-se cortes histológicos de músculo cardiaco de camundongo infectado com 
Lana AMA, Lages-Silva E, Barbosa AJA. Doença de Chagas congènita: avaliaçâo imunocitoquimica do parasitismo em tecidos de feto macerado. Revista da Sociedade Brasileira de Medicina Tropical 19: 95-98, Abr-Jun, 1986

tripomastigotas da cepa $Y$, sacrificado na fase aguda da infecção e apresentando numerosos amastigotas intracelulares nos diversos órgãos e tecidos. Como controle negativo utilizou-se soro de coelho normal ou PBS ao invés do anti-soro de coelho chagásico.

Os ninhos de amastigotas foram procurados minuciosamente e contados utilizando-se microscópio óptico binocular, tanto nas preparações coradas pelo H.E. como naquelas coradas pelo PAP. Para o exame das preparações coradas pelo H.E. utilizou-se a ampliação microscópica de $320 \mathrm{x}$ e, para aquelas coradas pelo PAP, a de $80 \mathrm{x}$.

\section{RESULTADOS}

\section{Cortes corados pelo H.E.}

Os diversos órgãos e tecidos fetais apresentaram focos de inflamação crônica. Esta foi mais intensa e freqüente nos tecidos musculares estriados esqueléticos e cardíaco e na musculatura lisa do esôfago. Nestes tecidos, associados ou não a processo inflamatório, foram observados ninhos de amastigotas do $T$, cruzi, em geral pouco numerosos e por vezes de difícil caracterização, aparentemente devido à autólise. Nesses casos os parasitas apresentavam coloração muito tênue, em geral não se evidenciando cinetoplasto $\mathrm{e}$ mesmo o núcleo, trazendo dificuldades ou impossibilitando o diagnóstico. Alguns ninhos situavam-se no interior de células volumosas, de citoplasma amplo e núcleo lobulado e hipercromático. $\mathrm{O}$ resultado da contagem dos ninhos de amastigotas, nos diversos fragmentos examinados, è dado na Tabela 1 .

Tabela 1 -Resultado das contagens do número de ninhos de amastigotas do Trypanosoma cruzi em cortes corados pelo método convencional (H.F.) e pelo método da peroxidase anti-peroxidase, de diferentes tecidos e órgãos de feto macerado de II-III graus em um caso de transmissão congênita da doenca de Chagas.

\begin{tabular}{lrrrrr}
\hline \multirow{2}{*}{ Tecido/Órgão } & \multicolumn{2}{c}{ No de cortes } & & \multicolumn{2}{c}{$\begin{array}{c}\text { No de ninhos } \\
\text { de amastigotas }\end{array}$} \\
\cline { 2 - 3 } \cline { 5 - 6 } & $H E$ & $P A P$ & & $H E$ & $P A P$ \\
\hline Músculo es- & 10 & 3 & & 11 & 11 \\
quelético & 5 & 2 & & 7 & 6 \\
Esófago & 2 & 2 & 2 & 9 \\
Língua & 5 & 3 & 3 & 22 \\
Miocárdio & 1 & 1 & 4 & 6 \\
Bexiga & 23 & 11 & 27 & 54 \\
\hline Total & & & & &
\end{tabular}

\section{Cortes corados pelo PAP}

Nos cortes histológicos corados pelo PAP os ninhos de amastigotas foram identificados com facilidade já na ampliação do microscópio de $80 x$ por exibirem coloraçào castanho-amarelada brilhante $\mathrm{e}$ serem bem delimitados dos tecidos circunvizinhos, estes fracamente corados pela hematoxilina (Fig. 1). Ampliaçōes maiores eram utilizadas em algumas áreas, apenas para confirmação diagnóstica, sendo excluidas da contagem imagens ou figuras que deixassem margem a dúvidas. Os resultados das contagens de ninhos de amastigotas nas preparaçōes coradas pelo PAP estão expressos na Tabela 1.

\section{DISCUSSĀO}

Os dados presentes na Tabela 1 mostram que os amastigotas foram diagnosticados em maior numero, por corte, nas preparaçoos coradas pelo PAP em relação àquelas coradas convencionalmente. Exemplificando, em 10 cortes de músculo esquelético identificaram-se 11 ninhos de amastigotas quando se usou a hematoxilina e eosina como corante (média de 1 ninho por corte) enquanto que em apenas três cortes do mesmo tecido corado pelo PAP identificou-se o mesmo número de ninhos. A proporção foi maior no miocárdio: enquanto em 5 cortes corados pelo H.E. observaram-se apenas 3 ninhos, em apenas 3 cortes corados pelo PAP observaram-se 22 ninhos. Esta desproporção de contagem entre os 2 métodos de coloração pode ser explicada, em parte, pela autólise tecidual observada em muitas áreas, prejudicando a identificação segura do parasitismo nas preparaçōes coradas pelo H.E. Além disso, foi observado nos cortes corados pelo PAP, que determinados ninhos eram geralmente muito pequenos, formados por poucos amastigotas, os quais dificilmente poderiam ser identificados através de coloração pelo H.E. Estes dados são importantes tambem do ponto de vista metodológico, quando indicam que a técnica imunocitoquimica pelo PAP, mesmo em material parcialmente autolisado, é útil e deve ter preferência sobre as preparaçōes convencionais para a identificação e quantificação do parasitismo.

No presente caso nào houve, desde o inicio, dúvidas quanto ao diagnóstico da infecção chagásica congênita graças aos dados clínicos positivos e exame da placenta bem como ao encontro de parasitas no interior de celulas gigantes de núcleos volumosos, lobulados e hipercromaticos encontradas na forma congenita da doença humana e descritas primeiramente por Rubio e Howard 7 . A técnica imunocitoquimica aqui empregada confirmou o diagnostico através da coloração especifica dos amastigotas, mesmo em tecidos autolisados, além de demonstrar para- 
Lana AMA, Lages-Silva E, Barbosa AJA. Doença de Chagas congênita. avaliááo imunocitoquimica do parasitismo em tecidos de feto macerado. Revista da Sociedade Brasileira de Medicina Tropical 19: 95-98, Abr-Iun, 1986

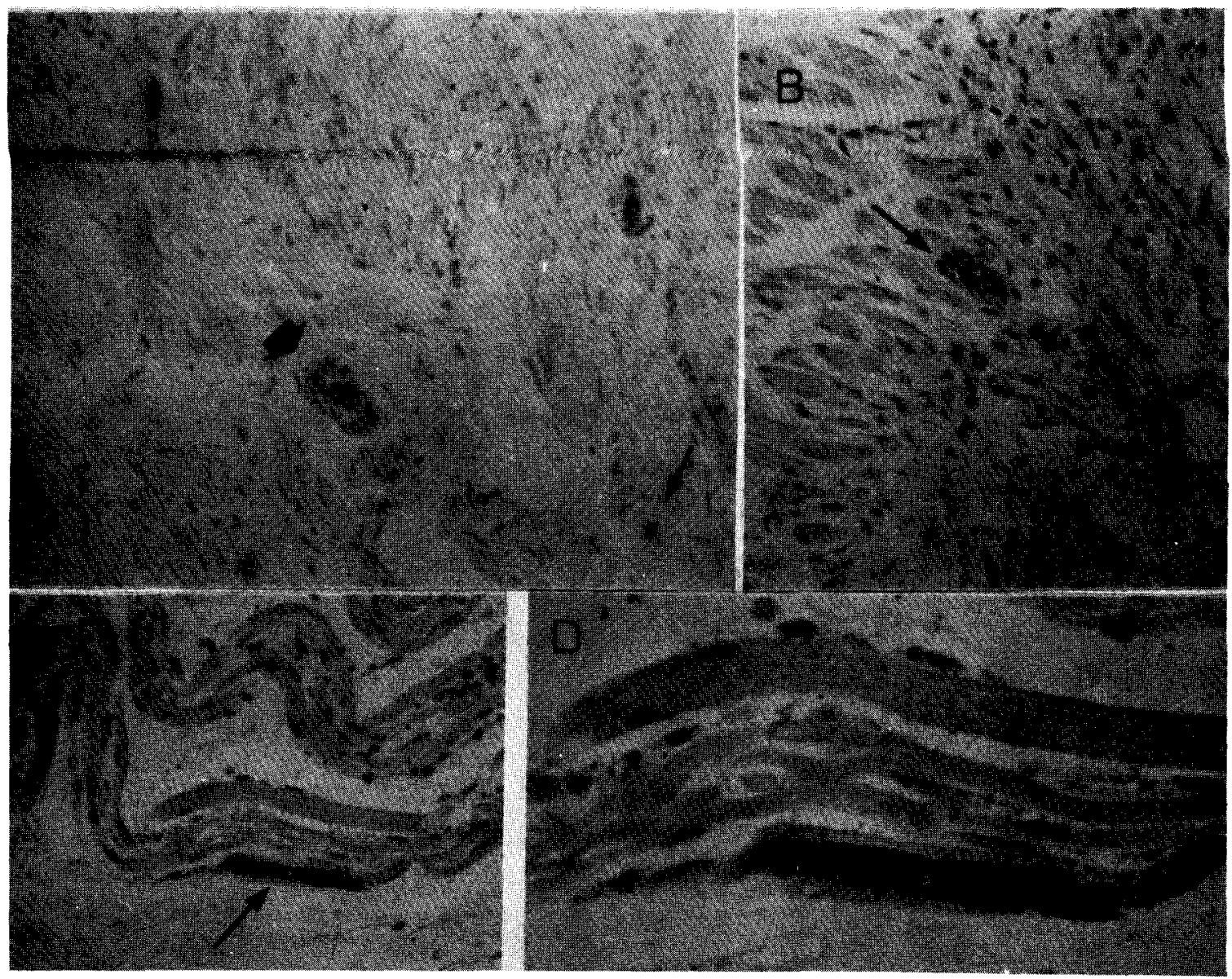

Figura 1 - Preparaçôes histológicas coradas pelo método da peroxidase antiperoxidase para evidenciar amastigotas do Trypanosoma cruzi em tecidos de feto macerado (humano). Contracoloração: hematoxilina. A-Parede muscular de bexiga apresentando 4 ninhos de amastigotas, um deles no interior de célula gigante de núcleo lobulado (seta grossa) e outro de dimensóes bastante diminutas (seta fina); $B$-Musculatura estriada de lingua. Amastigotas fortemente corados formando pequeno ninho no interior de célula muscular (seta); $C$ - Tecido muscular estriado esquelético. Presença de volumoso ninho de amastigotas (seta); $D$ - Mesmo tecido visto em $C$; observar a mastigotas fortemente corados $e$ fibras musculares em estado avançado de autolise. $A, B$ e C, 200x; D, 500x.

sitismo mais intenso que o observado na coloraçào pelo H.E. Com base neste resultado, imagina-se que o método PAP pode mostrar-se especialmente valioso. ou mesmo indispensável, nos casos que escapam ao diagnóstico clínico, ou quando a placenta não é examinada, e nos quais a avaliaçào histopatológica convencional for dificil em virtude de pequeno grau de parasitismo ou em decorrência de autólise.

\section{SUMMARY}

In order to specifically stain the Trypanosoma cruzi amastigotes, the immunocytochemical peroxi- dase anti peroxidase method was carried out in advanced macerated premature tissues of a case of human congenital Chagas' disease. The results have shown that the immunoctochemical method markedly improved the identification of the tissue parasitism when compared with the hematoxylin and eosin stain, even in advanced autolysed tissues.

Ke? Words: Poroxidase ante-peroxidase lech nique. Congenital Chagas' disease. Fetal maceration. Trypanosoma cruzi.

\section{REFERENCIAS BIBLIOGRAFICAS}

1. Araujo MOG, Jacomo HH. Yunes MAF. Doenç̧il de Chagas congenita em Brasilia. Apresentaçao de 28 
Lana AMA, Lages-Silva E, Barbosa AJA. Doença de Chagas congênita: avaliação imunocitoquímica do parasitismo em tecidos de feto macerado. Revista da Sociedade Brasileira de Medicina Tropical 19: 95-98, Abr-Jun, 1986

casos. In: Anais do XV Congresso Brasileiro de Patolo gia, Natal, 1983.

2. Barbosa AJA. Mètodo imunocitoquimico para a identificação de amastigotas de Trypanosoma cruzi em cortes histologicos de rotina. Revista do Instituto de Medicina Tropical de Sào Paulo 27: 293-297, 1985.

3. Bittencourt AL. Congenital Chagas disease. American Journal of Disease in Childhood 130:97-103, 1976.

4. Bittencourt AL, Sadigursky M. Barbosa HS. Doença de Chagas congenita. Estudo de 29 casos. Revista do Instituto de Medicina Tropical de Sào Paulo 17:146159. 1975 .

5. Bittencourt AL. Barbosa HS. A importància do estudo do feto macerado para o diagnóstico da forma congênita da doença de Chagas. Revista do Instituto de Medicina Tropical de Sào Paulo 14:260-263, 1972.

6. Krettli AU, Weiss-Carrington P. Nussenzweig RS. Membrane bound antibodies of bloodstream Trypanosoma cruzi in mice: strain differences in susceptibility to complement-mediated lysis. Clinical and Experimental Immunology 37:416-423, 1979.

7. Rubio M. Howard J. Observación de células gigantes parasitadas por Trypanosoma cruzi en niños con enfermedad de Chagas congenita. Biologica 34:50-60. 1963.

8. Sternberger L. Immunocytochemistry, 2a ed. In: John Wyley and Sons. New York. Chichester. Brisbane. Toronto. p. 104-169. 1979. 